\title{
Laparoscopic and Robotic Surgeries for Patients With Colorectal Cancer Who Have Had a Previous Abdominal Surgery
}

\author{
Soeun Park, Jeonghyun Kang, Eun Jung Park, Seung Hyuk Baik, Kang Young Lee \\ Department of Surgery, Yonsei University College of Medicine, Seoul, Korea
}

Purpose: The impact of previous abdominal surgery (PAS) on surgical outcomes from laparoscopic and robot surgeries is inconclusive. This study aimed to investigate the impact of PAS on perioperative outcomes from laparoscopic and robotic colorectal surgeries.

Methods: From March 2007 to February 2014, a total of 612 and 238 patients underwent laparoscopic and robotic surgeries, respectively. Patients were divided into 3 groups: those who did not have a PAS (NPAS), those who had a major PAS, and those who had a minor PAS. We further divided the patients so that our final groups for analysis were: patients with NPAS $(\mathrm{n}=478)$, major PAS $(\mathrm{n}=19)$, and minor PAS $(\mathrm{n}=115)$ in the laparoscopy group, and patients with NPAS $(\mathrm{n}=$ 202) and minor PAS $(n=36)$ in the robotic surgery group.

Results: In the laparoscopy group, no differences in the conversion rates between the 3 groups were noted (NPAS $=1.0 \%$ vs. major PAS $=0 \%$ vs. minor PAS $=1.7 \%, \mathrm{P}=0.701)$. In the robotic surgery group, the conversion rate did not differ between the NPAS group and the minor PAS group $(1.0 \%$ vs. $2.8 \%, \mathrm{P}=0.390)$. Among the groups, neither the operation time, blood loss, days to soft diet, length of hospital stay, nor complication rate were affected by PAS.

Conclusion: PAS did not jeopardize the perioperative outcomes for either laparoscopic or robotic colorectal surgeries. Therefore, PAS should not be regarded as an absolute contraindication for minimally invasive colorectal surgeries.

\section{Keywords: Colectomy; Laparoscopy; Robot; Colorectal surgery; Previous abdominal surgery}

\section{INTRODUCTION}

Since its first application for the treatment of colorectal disease in 1991, laparoscopy surgery, compared with open surgery, has yielded better recovery outcomes and similar oncologic outcomes in the management of colon and rectal cancers [1-3]. Since the in-

Received: April 25, 2017 - Accepted: July 20, 2017

Correspondence to: Jeonghyun Kang, M.D.

Department of Surgery, Gangnam Severance Hospital, Yonsei University College of Medicine, 211 Eonju-ro, Gangnam-gu, Seoul 06273, Korea Tel: +82-2-2019-3369, Fax: +82-2-3462-5994, E-mail: ravic@naver.com

Part of this paper was selected for a poster presentation at the Annual Meeting of the American Society of Colon and Rectal Surgeons in 2016 in Los Angeles, USA.

(C) 2017 The Korean Society of Coloproctology

This is an open-access article distributed under the terms of the Creative Commons Attribution NonCommercial License (http://creativecommons.org/licenses/by-nc/4.0) which permits unrestricted noncommercial use, distribution, and reproduction in any medium, provided the original work is properly cited. troduction of robotic surgery in the early 2000s, many studies have evaluated the safety and feasibility of robotic colorectal cancer surgery [4-6]; however, its cost-effectiveness compared to that of laparoscopic surgery remains controversial [7-9].

Adhesions from previous abdominal surgeries may affect surgical outcomes. In patients with postoperative adhesions, gaining safe access to the peritoneal cavity can be difficult, and blind insertion using a Veress needle may be dangerous. Also, placing trocars in the appropriate locations may not be possible. Adhesiolysis is occasionally necessary to uncover the planned trocar site, which could increase the overall operation time. Most importantly, severe adhesions may distort normal anatomical structures. Limited vision or reduced haptic sensation during laparoscopic and robotic surgeries may hinder the surgeon in his or her attempt to overcome the inherent limitations caused by previous adhesions [10].

While several studies have reported that a history of previous abdominal surgery (PAS) does not affect perioperative outcomes 
in laparoscopic colorectal surgeries $[10,11]$, several other studies have reported that patients with PAS are more likely to have prolonged operation time, significantly higher incidence of open conversion, an inadvertent enterotomy, or postoperative ileus than patients without PAS [12-16]. Recent studies that divided PAS patients into major or minor subgroups found that patients with major PAS, but not minor PAS, had a higher conversion rate or complication rate than patients without a PAS history $[17,18]$. Additionally, few studies on the effect of PAS on robotic colorectal surgery outcomes have been reported.

Although the safety and the advantages of laparoscopic and robotic colorectal surgeries have been confirmed, the use of both modalities in patients with a PAS history remains uncertain. Herein, we investigated the impact of PAS on perioperative recovery outcomes from laparoscopic and robotic colorectal surgeries.

\section{METHODS}

\section{Patients}

Between March 2007 and February 2014, a total of 850 patients underwent laparoscopy or robotic colorectal surgery at Gangnam Severance Hospital, Yonsei University College of Medicine. Among them, 612 patients underwent laparoscopic surgeries, and 238 patients underwent robotic surgery. Informed consent was obtained prior to surgery. This study was approved by the Gangnam Severance Hospital's Institutional Review Board (3-20160166).

During the study period, 3 surgeons performed all laparoscopic colorectal surgeries, and 2 surgeons performed all robotic colorectal surgeries. The standard surgical modality for patients with rectal cancer was either a total mesorectal excision or a tumor-specific mesorectal excision. For left-side tumors, at the discretion of the surgeon, the inferior mesenteric artery was ligated at the level of its origin or just below the left colic artery. For right-side tumors, principal vessel ligation depended on the tumor's location. The right branch of the middle colic vessels was usually transected in patients with cecal or ascending colon cancer. The middle colic vessels were ligated from the superior mesenteric vessels at their origin if the tumor was located at the hepatic flexure or proximal transverse colon. Vessel ligation and mobilization of the bowel were performed intracorporeally in most cases. Bowel transection and anastomosis were performed either intracorporeally or extracorporeally, according to tumor's location and surgeon's preference. No principle difference in surgical techniques between the laparoscopic and robotic surgeries was noted. For patients with locally advanced rectal cancers, preoperative chemoradiotherapy was performed when the patient was diagnosed as having clinical T3/4 disease and/or node-positive stage. However, the application depended on the tumor's height (occasionally omitted if the tumor was located in the upper rectum) or surgeon's discretion.

Initially, patients were divided into 2 groups: those who had un- dergone a PAS and those who had not (NPAS). PAS was defined as any type of open or laparoscopic abdominal procedure that invaded the peritoneal space and, thus, could induce peritoneal adhesions. Hernioplasty, hemorrhoidectomy, and endoscopic procedures were not included as PASs for this study. Additionally, we divided PAS patients into major PAS and minor PAS groups according to the classification suggested by Kim et al. [17], who defined major PAS as abdominal surgery involving more than one abdominal quadrant and minor PAS as abdominal surgery involving one abdominal quadrant. A laparoscopic cholecystectomy or appendectomy, as well as a low midline incision for gynecologic surgeries, including an oophorectomy, salpingectomy, cesarean section, or myomectomy, were classified as minor PASs [17].

The patients' clinicopathologic characteristics (sex, age, body mass index [BMI], American Society of Anesthesiologist [ASA] physical status classification, tumor location, tumor size, preoperative chemoradiotherapy, and stage), abdominal surgery history, and perioperative outcomes (combined resection, conversion, operation time, blood loss, number of retrieved lymph nodes, days to soft diet intake, length of hospital stay, and postoperative complications) were retrieved from a prospectively maintained database. Conversion was defined as any case that could not be completed with the intended laparoscopic or robotic surgical approach and that required a more extensive abdominal incision than expected for specimen removal. Each factor was compared between the NPAS, major PAS, and minor PAS subgroups within the laparoscopy group and between the NPAS and minor PAS subgroups within the robotic surgery group.

\section{Statistical analyses}

All calculations were performed using IBM SPSS Statistics ver. 23.0 (IBM Co., Armonk, NY, USA). The differences in clinicopathologic features and perioperative outcomes among the different surgery groups were analyzed using a 2-tailed Pearson chisquare test or Fisher exact test for categorical variables and Student t-test or Mann-Whitney U-test for continuous variables. The Kruskal-Wallis test was used to analyze quantitative differences between the the groups. A P-value of $<0.05$ was considered statistically significant.

\section{RESULTS}

In the laparoscopy group, 19 (3.1\%) and 115 patients (18.7\%) were allocated to the major and the minor PAS subgroups, respectively. In the robotic surgery group, 36 patients $(15.1 \%)$ were allocated to the minor PAS subgroup and no patients were allocated to the major PAS subgroup. Among major PAS patients, a gastrectomy was the most common surgery, followed by small bowel resection. Among minor PAS patients, an appendectomy was the most frequently performed procedure, followed by a total abdominal hysterectomy, in both the laparoscopy and the robotic surgery groups (Table 1). 
Table 1. Types of previous abdominal surgeries

\begin{tabular}{|c|c|c|}
\hline Surgery type & $\begin{array}{c}\text { Laparoscopy } \\
\text { group } \\
(\mathrm{n}=134)\end{array}$ & $\begin{array}{l}\text { Robotic } \\
\text { surgery group } \\
(n=36)\end{array}$ \\
\hline \multicolumn{3}{|l|}{ Major PAS $(n=19)$} \\
\hline Gastrectomy & $5(26.3)$ & - \\
\hline Small bowel resection & $3(15.8)$ & - \\
\hline Hepatectomy & $2(10.5)$ & - \\
\hline Gastrectomy, cholecystectomy & $1(5.3)$ & - \\
\hline Gastrectomy, small bowel resection & $1(5.3)$ & - \\
\hline Low anterior resection, Wedge resection of liver & $1(5.3)$ & - \\
\hline Nephrectomy for organ transplantation & $1(5.3)$ & - \\
\hline Distal pancreatectomy & $1(5.3)$ & - \\
\hline Right hemicolectomy & $1(5.3)$ & - \\
\hline Right hemicolectomy, Whipple operation & $1(5.3)$ & - \\
\hline Roux-en-Y choledochojejunostomy & $1(5.3)$ & - \\
\hline Small bowel resection, TAH & $1(5.3)$ & - \\
\hline Minor PAS & $n=151$ & $\mathrm{n}=36$ \\
\hline Appendectomy & $51(44.3)$ & $11(30.6)$ \\
\hline Total abdominal hysterectomy & $17(14.8)$ & $9(25.0)$ \\
\hline Cesarean section & $15(13.0)$ & $6(16.7)$ \\
\hline Cholecystectomy & $10(8.7)$ & $5(13.9)$ \\
\hline Myomectomy & $4(3.5)$ & - \\
\hline Oophorectomy & $4(3.5)$ & $1(2.8)$ \\
\hline Tubal ligation & $3(2.6)$ & - \\
\hline Cesarean section, appendectomy & $2(1.7)$ & - \\
\hline Cholecystectomy, appendectomy & $2(1.7)$ & - \\
\hline TAH, appendectomy & $2(1.7)$ & $2(5.6)$ \\
\hline TAH, cholecystectomy & $2(1.7)$ & - \\
\hline Cesarean section, cholecystectomy & $1(0.9)$ & - \\
\hline Operation due to ectopic pregnancy & $1(0.9)$ & $1(2.8)$ \\
\hline TAH, Cesarean section & $1(0.9)$ & - \\
\hline Abscess drainage & - & $1(2.8)$ \\
\hline
\end{tabular}

Values are presented as number (\%).

PAS, previous abdominal surgery; TAH, total abdominal hysterectomy.

Overall, both the laparoscopy and robotic groups had significantly more women with PAS. However, a predominance of men was found among major PAS patients compared with minor PAS patients in the laparoscopy group. Also, in the laparoscopy group, major PAS patients tended to be older than minor PAS patients, although the difference was not statistically significant $(\mathrm{P}=0.057)$. Rectal cancer was significantly more common in the major PAS subgroup than the minor PAS and the NPAS subgroups $(\mathrm{P}=$ 0.012). No differences in body mass index (BMI), ASA physical status classification, tumor size, preoperative chemoradiotherapy, or stage among the NPAS, major PAS, and minor PAS subgroups were observed. In the robotic surgery group, no significant differences were found regarding age, BMI, ASA physical status classification, tumor location, tumor size, preoperative chemoradiotherapy, or stage between the PAS and the minor NPA subgroups (Table 2).

Conversion to open surgery was required for 7 patients (1.1\%) in the laparoscopy group and 3 patients (1.2\%) in the robotic surgery group. In the laparoscopy group, no differences in conversion rates were found between the 3 subgroups (NPAS $=1.0 \%$ vs. major PAS $=0 \%$ vs. minor $\mathrm{PAS}=1.7 \%, \mathrm{P}=0.701)$. The mean operation time, blood loss, and number of retrieved lymph nodes were not significantly different between the 3 subgroups. The median time to resuming a soft diet was 3 days (range, 2-33 days) for the NPAS subgroup, 3 days (range, 2-5 days) for the major PAS subgroup, and 3 days (range, 1-16 days) for the minor PAS subgroup $(\mathrm{P}=0.804)$. Median hospital stay length was 7 days (range, 3-44 days) for the NPAS subgroup, 7 days (range, 4-34 days) for the major PAS subgroup, and 7 days (range, 4-56 days) for the minor PAS subgroup $(\mathrm{P}=0.992)$.

In the robotic surgery group, the conversion rate did not differ between the NPAS subgroup and the minor PAS subgroup (1.0\% vs. $2.8 \%, \mathrm{P}=0.390)$. No significant differences in operation time, blood loss, and number of harvested lymph nodes were noted between the NPAS and the minor PAS subgroups. The median time for resuming a soft diet was 5 days (range, 2-55 days) in the NPAS subgroup and 5 days (range, $2-23$ days; $\mathrm{P}=0.393$ ) in the minor PAS group. Median hospital stay length was 9 days (range, 5-67 days) in the NPAS subgroup and 8 days (range, 6-30 days; $P$ $=0.136$ ) in the minor PAS subgroup (Table 3).

In the laparoscopy group, the complication rate did not differ between the 3 subgroups (NPAS subgroup $=13.6 \%$ vs. major PAS sub group $=26.3 \%$ vs. minor PAS sub group $=16.5 \% ; P=0.229$ ). In the robotic surgery group, total complications did not differ between the NPAS and the minor PAS subgroups $(\mathrm{P}=0.264)($ Table 4$)$.

\section{DISCUSSION}

Our study demonstrated that PAS did not jeopardize immediate postoperative outcomes among patients who received either laparoscopic or robotic colorectal surgery. This suggests that colorectal cancer patients with a PAS can safely undergo minimally invasive surgeries.

Intra-abdominal adhesions are almost inevitable after abdominal surgery. In a clinical study, $83 \%$ of patients with PAS had adhesions along abdominal openings whereas only $7 \%$ of patients without PAS had adhesions [19]. Peritoneal inflammation, remesothelialization, macrophage inflow, and fibrin gel matrix organization can induce adhesion formation [20]. Generally, reoperation on a patient with PAS would be difficult and risky because adhesiolysis is usually required to access the operation field for complete oncologic resection. This process prolongs the opera- 
Table 2. Clinicopathological characteristics according to history of previous abdominal surgery for the patients in the laparoscopy and robotic surgery groups

\begin{tabular}{|c|c|c|c|c|c|c|c|}
\hline \multirow[b]{2}{*}{ Variable } & \multicolumn{4}{|c|}{ Laparoscopy group } & \multicolumn{3}{|c|}{ Robotic surgery group } \\
\hline & $\begin{array}{c}\text { NPAS } \\
(\mathrm{n}=478)\end{array}$ & $\begin{array}{c}\text { Major PAS } \\
(n=19)\end{array}$ & $\begin{array}{c}\text { Minor PAS } \\
(\mathrm{n}=115)\end{array}$ & P-value & $\begin{array}{c}\text { NPAS } \\
(\mathrm{n}=202)\end{array}$ & $\begin{array}{c}\text { Minor PAS } \\
(n=36)\end{array}$ & P-value \\
\hline Sex & & & & $<0.001$ & & & $<0.001$ \\
\hline Male & 307 (64.2) & $13(68.4)$ & $41(35.7)$ & & $141(69.8)$ & 12 (33.3) & \\
\hline Female & $171(35.8)$ & $6(31.6)$ & $74(64.3)$ & & $61(30.2)$ & $24(66.7)$ & \\
\hline Age (yr) & $62.4 \pm 2.0$ & $68.4 \pm 8.9$ & $61.4 \pm 1.4$ & 0.057 & $60.7 \pm 11.8$ & $59.5 \pm 11.3$ & 0.554 \\
\hline $\mathrm{BMI}\left(\mathrm{kg} / \mathrm{m}^{2}\right)$ & $23.5 \pm 3.1$ & $22.3 \pm 2.8$ & $23.5 \pm 3.0$ & 0.296 & $23.4 \pm 2.9$ & $23.7 \pm 3.4$ & 0.561 \\
\hline ASA PS classification & & & & $0.160^{a}$ & & & $0.810^{\circ}$ \\
\hline I & $184(38.5)$ & $6(31.6)$ & $42(36.5)$ & & $138(68.3)$ & $23(63.9)$ & \\
\hline$\|$ & $214(44.8)$ & $6(31.6)$ & $58(50.4)$ & & 60 (29.9) & $12(34.3)$ & \\
\hline III & $80(16.7)$ & $7(36.8)$ & $15(13.0)$ & & $3(1.5)$ & $0(0)$ & \\
\hline Tumor location & & & & $0.012^{a}$ & & & 0.752 \\
\hline Colon & $374(78.2)$ & $9(47.4)$ & $89(77.4)$ & & $73(36.1)$ & $14(38.9)$ & \\
\hline Rectum & $104(21.8)$ & $10(52.6)$ & $26(22.6)$ & & $129(63.9)$ & $22(61.1)$ & \\
\hline Tumor size (cm) & & & & $0.574^{a}$ & & & 0.821 \\
\hline$\leq 5$ & $369(77.2)$ & $13(68.4)$ & $87(75.7)$ & & $155(76.7)$ & $27(75.0)$ & \\
\hline$>5$ & $109(22.8)$ & $6(31.6)$ & 28 (24.3) & & 47 (23.3) & $9(25.0)$ & \\
\hline Preoperative CRT & $31(6.5)$ & $2(10.5)$ & $5(4.3)$ & $0.413^{\mathrm{a}}$ & $27(13.4)$ & $2(5.6)$ & $0.270^{2}$ \\
\hline Stage & & & & $0.053^{\mathrm{a}}$ & & & $0.147^{\circ}$ \\
\hline 0 & $4(0.8)$ & $0(0)$ & $3(2.6)$ & & $6(3.0)$ & 2 (5.6) & \\
\hline I & $137(28.7)$ & $9(47.4)$ & 21 (18.3) & & $58(28.7)$ & 7 (19.4) & \\
\hline$\|$ & 135 (28.2) & 2 (10.5) & $38(33.0)$ & & $62(30.7)$ & 7 (19.4) & \\
\hline III & $171(35.8)$ & $6(31.6)$ & 42 (36.5) & & 71 (35.1) & $18(50.0)$ & \\
\hline IV & $31(6.5)$ & $2(10.5)$ & $11(9.6)$ & & $5(2.5)$ & $2(5.6)$ & \\
\hline
\end{tabular}

Values are presented as number (\%) or mean \pm standard deviation.

PAS, previous abdominal surgery; NPAS, non-PAS; BMI, body mass index; ASA PS, American Society of Anesthesiologist physical status; CRT, chemoradiotherapy. aFisher exact test.

Table 3. Perioperative outcomes between the groups according to operative technique

\begin{tabular}{|c|c|c|c|c|c|c|c|}
\hline \multirow[b]{2}{*}{ Variable } & \multicolumn{4}{|c|}{ Laparoscopy group } & \multicolumn{3}{|c|}{ Robotic surgery group } \\
\hline & $\begin{array}{c}\text { NPAS } \\
(n=478)\end{array}$ & $\begin{array}{c}\text { Major PAS } \\
(n=19)\end{array}$ & $\begin{array}{c}\text { Minor PAS } \\
(n=115)\end{array}$ & P-value & $\begin{array}{c}\text { NPAS } \\
(\mathrm{n}=202)\end{array}$ & $\begin{array}{l}\text { Minor PAS } \\
(n=36)\end{array}$ & P-value \\
\hline Combined resection & $66(13.8)$ & $1(5.3)$ & $23(20.0)$ & $0.151^{\mathrm{a}}$ & $19(9.4)$ & $6(16.7)$ & $0.233^{\mathrm{a}}$ \\
\hline Open conversion & $5(1.0)$ & $0(0)$ & $2(1.7)$ & $0.701^{\mathrm{a}}$ & $2(1.0)$ & $1(2.8)$ & $0.390^{\mathrm{a}}$ \\
\hline Operation time (min) & $245 \pm 85$ & $275 \pm 133$ & $253 \pm 96$ & 0.258 & $273 \pm 96$ & $268 \pm 85$ & 0.770 \\
\hline Blood loss (mL) & $126 \pm 212$ & $86 \pm 125$ & $137 \pm 291$ & 0.653 & $131 \pm 179$ & $189 \pm 221$ & 0.148 \\
\hline No. of retrieved lymph nodes & $25.3 \pm 16.8$ & $20.4 \pm 10.2$ & $25.4 \pm 16.2$ & 0.453 & $18.4 \pm 11.2$ & $22.6 \pm 20.2$ & 0.229 \\
\hline Days to soft diet intake & $3(2-33)$ & $3(2-5)$ & $3(1-16)$ & $0.804^{b}$ & $5(2-55)$ & $5(2-23)$ & $0.393^{c}$ \\
\hline Length of hospital stay (day) & $7(3-44)$ & $7(4-34)$ & $7(4-56)$ & $0.992^{b}$ & $9(5-67)$ & $8(6-30)$ & $0.136^{c}$ \\
\hline
\end{tabular}

Values are presented as number (\%), mean \pm standard deviation, or median (range).

PAS, previous abdominal surgery; NPAS, non-PAS.

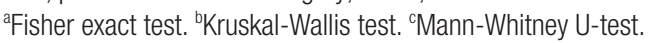


Table 4. Comparison of morbidity between the groups according to operative technique

\begin{tabular}{|c|c|c|c|c|c|c|c|}
\hline \multirow[b]{2}{*}{ Variable } & \multicolumn{4}{|c|}{ Laparoscopy group } & \multicolumn{3}{|c|}{ Robotic surgery group } \\
\hline & $\begin{array}{c}\text { NPAS } \\
(n=478)\end{array}$ & $\begin{array}{c}\text { Major PAS } \\
(n=19)\end{array}$ & $\begin{array}{c}\text { Minor PAS } \\
(n=115)\end{array}$ & P-value & $\begin{array}{c}\text { NPAS } \\
(n=202)\end{array}$ & $\begin{array}{c}\text { Minor PAS } \\
(n=36)\end{array}$ & P-value \\
\hline Complications & $65(13.6)$ & $5(26.3)$ & $19(16.5)$ & $0.229^{a}$ & $38(18.8)$ & $4(11.1)$ & 0.264 \\
\hline Wound infection & $15(3.1)$ & $0(0)$ & $3(2.6)$ & $1.000^{\mathrm{a}}$ & $3(1.5)$ & $0(0)$ & $1.000^{\circ}$ \\
\hline Anastomotic leakage & $11(2.3)$ & $1(5.3)$ & $4(3.5)$ & $0.304^{\mathrm{a}}$ & $14(6.9)$ & $1(2.8)$ & $0.480^{\mathrm{a}}$ \\
\hline Bleeding & $4(0.8)$ & $0(0)$ & $0(0)$ & $1.000^{\mathrm{a}}$ & $4(2.0)$ & $0(0)$ & $1.000^{\circ}$ \\
\hline Abdominal abscess & - & - & - & - & $1(0.5)$ & $0(0)$ & $1.000^{\mathrm{a}}$ \\
\hline Postoperative ileus & $9(1.9)$ & $1(5.3)$ & $1(0.9)$ & $0.313^{a}$ & $2(1.0)$ & $2(5.6)$ & $0.110^{\mathrm{a}}$ \\
\hline Urinary retention & $17(3.6)$ & $2(10.5)$ & $6(5.2)$ & $0.167^{\mathrm{a}}$ & $10(5.0)$ & $0(0)$ & $0.367^{a}$ \\
\hline Other & $9(1.9)$ & $1(5.3)$ & $5(4.3)$ & $0.180^{\mathrm{a}}$ & $4(2.0)$ & $1(2.8)$ & $0.563^{a}$ \\
\hline
\end{tabular}

Values are presented as number (\%).

PAS, previous abdominal surgery; NPAS, non-PAS.

aFisher exact test.

Table 5. Clinical outcomes between the NPAS and the PAS groups from previous studies (laparoscopic surgeries)

\begin{tabular}{lrrcccc}
\hline \multirow{2}{*}{ Study } & NPAS & \multirow{2}{*}{ PAS } & \multicolumn{4}{c}{ Comparison between NPAS and PAS } \\
\cline { 5 - 7 } & & & Operation time (min) & Conversion rate (\%) & Complication rate (\%) & LOH \\
\hline Law et al. [10] (2005) & 211 & 84 & $170 / 180$ & $11.3 / 17.8$ & $20.8 / 16.7$ & N/A \\
Franko et al. [12] (2006) & 473 & 347 & $158 / 159$ & $11.4^{*} / 19.6^{*}$ & N/A (median) \\
Arteaga González et al. [13] (2006) & 59 & 27 & $199 / 222$ & $5.1^{*} / 26.1^{*}$ & $38.9 / 39.1$ & $7.6 / 6.3$ (mean) \\
Vignali et al. [14] (2007) & 91 & 91 & $192^{*} / 218^{*}$ & $8.7 / 16.4$ & $23.1 / 25.3$ & $9.1 / 9.9$ (median) \\
Naguib et al. [11] (2012) & 113 & 68 & $216 / 233$ & $10.6 / 13.2$ & $24.7 / 25$ & $4.5 / 4$ (median) \\
Yamamoto et al. [15] (2013) & 1,121 & 580 & $244 / 242$ & $10.2 / 12.4$ & $23.3 / 25.3$ & $18.8 / 19$ (mean) \\
Zeng et al. [16] (2015) & 378 & 378 & $200^{*} / 220^{*}$ & $9.5^{*} / 16.6^{*}$ & $20.6 / 19$ & $9 / 9$ (median) \\
\hline
\end{tabular}

PAS, previous abdominal surgery; NPAS, non-PAS; LOH, length of hospital stay; N/A, not available.

*Statistically significant.

tion time $[19,21]$ and increases the risk of intraoperative bleeding, inadvertent enterotomy or enterectomy $[22,23]$. The surgery can be disturbed by adhesions that change the local anatomy and make distinguishing actual structures difficult. Laparoscopic and robotic surgeries are more likely to induce such damage than open surgeries because of the limited visual field during the initial approach and the loss of tactile sensation.

In Korea, the use of laparoscopy for colorectal surgery has increased to $64 \%$ of all colorectal cancer surgeries performed, and robotic surgery has become another way to perform minimally invasive colorectal surgeries $[4,24]$. Surgeons generally prefer laparoscopic and robotic colorectal surgeries because they usually yield earlier recovery of bowel function and shorter time to hospital discharge than open surgery $[1-6,25,26]$, although the costeffectiveness of robotic surgeries remains unclear in Korea [7-9]. However, PAS has been regarded as a relative contraindication for minimally invasive surgeries because intra-abdominal adhesions might increase technical difficulties.

In this study, the proportion of patients who had had previous abdominal surgeries was higher in women than in men, largely due to the preponderance of common gynecologic surgeries, such as a total abdominal hysterectomy, cesarean section, oophorectomy, and myomectomy. This was consistent with patient histories in other studies.

Existing studies have found contradictory impacts of PAS on operation time (Tables 5, 6). Most previous studies reported that PAS did not affect operation time [10-13, 15]. However, Vignali et al. [14] reported that the PAS group was associated with a longer operation time than the control group (218 minutes vs. $192 \mathrm{~min}$ utes, $\mathrm{P}=0.01$ ). Additionally, Zeng et al. [16] reported that in their case-matched cohort, the PAS group had a longer average operation time than the group without PAS (220 minutes vs. $200 \mathrm{~min}$ utes, $P=0.002)$. According to recent studies that also stratified PAS patients into minor or major PAS groups, Kim et al. [17] reported that the operation times were comparable for patients in the NPAS, the major PAS, and the minor PAS groups $(188,191$, and 192 minutes, respectively, for colon cancer and 227, 210, and 248 minutes, respectively, for rectal cancer). Lee et al. [18] also re- 
Table 6. Clinical outcomes between the among NPAS, major PAS, and minor PAS groups from previous studies (laparoscopic surgeries)

\begin{tabular}{|c|c|c|c|c|c|c|c|}
\hline \multirow{2}{*}{ Study } & \multirow{2}{*}{ NPAS } & \multirow{2}{*}{ Major PAS } & \multirow{2}{*}{ Minor PAS } & \multicolumn{4}{|c|}{ Comparison among NPAS, major PAS, and minor PAS } \\
\hline & & & & Operation time (min) & Conversion rate $(\%)$ & Complication rate $(\%)$ & $\mathrm{LOH}$ \\
\hline \multicolumn{8}{|l|}{ Kim et al. [17] (2015) } \\
\hline Rectal cancer & 282 & 16 & 26 & $227 / 210 / 248$ & $8.9^{\star} / 25^{\star} / 15.4$ & 29.1/25/26.9 & 14/13/13 (mean) \\
\hline Lee et al. [18] (2016) & 2,595 & 165 & 428 & $170 / 169 / 164$ & $1.7^{\star} / 4.2^{\star} / 2.1$ & $10.8^{*} / 17^{*} / 8.2$ & 9.1/9.5/8.8 (mean) \\
\hline Laparoscopy & 478 & 19 & 115 & $245 / 275 / 253$ & $1.0 / 0 / 1.7$ & 13.6/26.3/16.5 & 7/7/7 (median) \\
\hline Robot & 202 & 0 & 36 & 273/NA/268 & 1.0/NA/2.8 & 18.8/NA/11.1 & 9/NA/8 (median) \\
\hline
\end{tabular}

PAS, previous abdominal surgery; NPAS, non-PAS; LOH, length of hospital stay; N/A, not available.

*Statistically significant.

ported average operation times of 170,169, and 164 minutes for these 3 groups and found no differences among the groups. Our results are consistent with those of previous studies. Additionally, we found no difference in operation times between the NPAS and the minor PAS groups for robotic surgery. However, we need to interpret these results cautiously. Kim et al. [17] reported that major PAS in rectal cancer patients was associated with relatively longer operation time compared with patients with no PAS or minor PAS, although the difference was not statistically significant. They argued that the operation time could be greatly affected by specific time-demanding surgical procedures rather than the degree of adhesion, in that an abdominoperineal resection was more commonly performed in the NPAS group than in the major PAS or the minor PAS group. Also, the learning curve for laparoscopic surgery and the tendency for inexperienced surgeons to reject patients with PAS may make estimating the real impact of previous abdominal surgeries on operation time more difficult [18].

In cases with conversions, contradictory results were found among previous studies (Tables 5,6 ). Some studies found that PAS was associated with a higher conversion rate $[12,13,16]$ while some studies did not $[10,11,14,15]$. Interestingly, 2 recently published studies analyzed the conversion rate according to the major and the minor types of previous abdominal surgeries $[17,18]$. They found that major PAS, not minor PAS, was associated with a higher conversion rate compared with that for patients with no PAS. Although the definition of minor or major PAS was arbitrary and the characteristics of previous surgeries (either open or laparoscopic surgery) could not be accurately included in these 2 retrospective studies, the differences in adhesion formation according to PAS boundaries could, in part, explain the contradictory results among previous studies.

In Korean studies on laparoscopic colorectal surgeries, the open conversion rate was relatively low compared to that seen in Western countries. In the COREAN trial comparing open and laparoscopic surgery for patients with mid or low rectal cancer after neoadjuvant chemoradiotherapy, although the rate of previous abdominal surgeries was $45.3 \%$ in the laparoscopy group, the conversion rate was only $1.1 \%$ (2 of 170) [3]. Kim et al. [27] reported a conversion rate of $0.6 \%$ ( 1 of 143 ) even among early surgical trainees, where 70 cases were performed under the supervision of an experienced surgeon. In contrast, Park et al. [28] reported a significantly higher conversion rate (14.8\%) among obese patients $\left(\mathrm{BMI}>30 \mathrm{~kg} / \mathrm{m}^{2}\right)$ compared with other groups (2.6\% in patients with $\mathrm{BMI}<25 \mathrm{~kg} / \mathrm{m}^{2}, 2.9 \%$ in patients with BMI $=25-29.9 \mathrm{~kg} / \mathrm{m}^{2}$ ). These results suggest that the conversion rate was influenced not only by the degree of surgical expertise but also by the patient's physical status. The overall conversion rate in this study was similar to that from other Korean studies $(1.1 \%$ in laparoscopic and $1.2 \%$ in robotic surgeries). In contrast to other previous studies that compared 3 laparoscopy groups, previous abdominal surgeries did not impact the rate of conversion for either laparoscopic or robotic surgeries. One possible explanation might be the overall low conversion rate in our study. All of the laparoscopic and the robotic surgeries were completed by experienced colorectal surgeons, and the proportion of obese patients in our cohort was extremely low. However, the possibility of selection bias cannot be rejected because of our relatively small sample size, especially for the patients in the major PAS group who underwent laparoscopic surgery.

A major limitation of our study is its retrospective design. We were not able to include the incision site of previous abdominal surgeries among the variables affecting clinical outcomes. One of the specific characteristics of laparoscopic and robotic colorectal surgeries is that they require multiquadrant movements in the abdomen. Thus, surgical difficulties might depend on whether adhesions were present in the same operation field or if previous operations had been performed in the same abdominal quadrant. Yamamoto et al. [15] found that some situations, considering both previous incisional skin scarring and type of planned laparoscopic surgeries (e.g., transverse colectomy with median and upper median incisions, left colectomy with upper median incision, or total colectomy with median incision), showed higher conversion rates than others. The decision to perform laparoscopic, ro- 
botic, or open surgery was always between the surgeon and the patient. Because an objective assessment of how the surgical modality had been selected was not available, the reasoning behind each selection could not be determined. This may have led to a possible selection bias in which patients with severe adhesions from previous surgeries would be expected to experience difficulties with minimally invasive surgery and, thus, would be excluded from this study. This potential selection bias must be addressed with a future prospectively designed study. Finally, the small sample size of patients with major PAS may have led to an underpowered analysis; thus, we could not investigate the impact of major PAS on robotic surgeries, which will need further validation in other clinical settings.

In conclusion, our study demonstrated that having had PAS did not adversely impact short-term outcomes from laparoscopy or robot colorectal cancer surgeries. We should not regard PAS as an absolute contraindication for minimally invasive surgeries.

\section{CONFLICT OF INTEREST}

No potential conflict of interest relevant to this article was reported.

\section{REFERENCES}

1. Clinical Outcomes of Surgical Therapy Study Group, Nelson H, Sargent DJ, Wieand HS, Fleshman J, Anvari M, et al. A comparison of laparoscopically assisted and open colectomy for colon cancer. N Engl J Med 2004;350:2050-9.

2. Jayne DG, Guillou PJ, Thorpe H, Quirke P, Copeland J, Smith $\mathrm{AM}$, et al. Randomized trial of laparoscopic-assisted resection of colorectal carcinoma: 3-year results of the UK MRC CLASICC Trial Group. J Clin Oncol 2007;25:3061-8.

3. Kang SB, Park JW, Jeong SY, Nam BH, Choi HS, Kim DW, et al. Open versus laparoscopic surgery for mid or low rectal cancer after neoadjuvant chemoradiotherapy (COREAN trial): short-term outcomes of an open-label randomised controlled trial. Lancet Oncol 2010;11:637-45.

4. Kang J, Yoon KJ, Min BS, Hur H, Baik SH, Kim NK, et al. The impact of robotic surgery for mid and low rectal cancer: a casematched analysis of a 3-arm comparison--open, laparoscopic, and robotic surgery. Ann Surg 2013;257:95-101.

5. Baek JH, Pastor C, Pigazzi A. Robotic and laparoscopic total mesorectal excision for rectal cancer: a case-matched study. Surg Endosc 2011;25:521-5.

6. Park JS, Choi GS, Lim KH, Jang YS, Jun SH. Robotic-assisted versus laparoscopic surgery for low rectal cancer: case-matched analysis of short-term outcomes. Ann Surg Oncol 2010;17:3195202.

7. Park JS, Choi GS, Park SY, Kim HJ, Ryuk JP. Randomized clinical trial of robot-assisted versus standard laparoscopic right colectomy. Br J Surg 2012;99:1219-26.
8. Kim CW, Baik SH, Roh YH, Kang J, Hur H, Min BS, et al. Costeffectiveness of robotic surgery for rectal cancer focusing on short-term outcomes: a propensity score-matching analysis. Medicine (Baltimore) 2015;94:e823.

9. Kang J, Park YA, Baik SH, Sohn SK, Lee KY. A comparison of open, laparoscopic, and robotic surgery in the treatment of rightsided colon cancer. Surg Laparosc Endosc Percutan Tech 2016;26: 497-502.

10. Law WL, Lee YM, Chu KW. Previous abdominal operations do not affect the outcomes of laparoscopic colorectal surgery. Surg Endosc 2005;19:326-30.

11. Naguib N, Saklani A, Shah P, Mekhail P, Alsheikh M, AbdelDayem M, et al. Short-term outcomes of laparoscopic colorectal resection in patients with previous abdominal operations. J Laparoendosc Adv Surg Tech A 2012;22:468-71.

12. Franko J, O'Connell BG, Mehall JR, Harper SG, Nejman JH, Zebley DM, et al. The influence of prior abdominal operations on conversion and complication rates in laparoscopic colorectal surgery. JSLS 2006;10:169-75.

13. Arteaga González I, Martín Malagón A, López-Tomassetti Fernández EM, Arranz Durán J, Díaz Luis H, Carrillo Pallares A. Impact of previous abdominal surgery on colorectal laparoscopy results: a comparative clinical study. Surg Laparosc Endosc Percu$\tan$ Tech 2006;16:8-11.

14. Vignali A, Di Palo S, De Nardi P, Radaelli G, Orsenigo E, Staudacher C. Impact of previous abdominal surgery on the outcome of laparoscopic colectomy: a case-matched control study. Tech Coloproctol 2007;11:241-6.

15. Yamamoto M, Okuda J, Tanaka K, Kondo K, Asai K, Kayano H, et al. Effect of previous abdominal surgery on outcomes following laparoscopic colorectal surgery. Dis Colon Rectum 2013;56:33642.

16. Zeng WG, Liu MJ, Zhou ZX, Hou HR, Liang JW, Wang Z, et al. Impact of previous abdominal surgery on the outcome of laparoscopic resection for colorectal cancer: a case-control study in 756 patients. J Surg Res 2015;199:345-50.

17. Kim IY, Kim BR, Kim YW. Impact of prior abdominal surgery on rates of conversion to open surgery and short-term outcomes after laparoscopic surgery for colorectal cancer. PLoS One 2015;10: e0134058.

18. Lee SY, Kim CH, Kim YJ, Kim HR. Laparoscopic surgery for colorectal cancer patients who underwent previous abdominal surgery. Surg Endosc 2016;30:5472-80.

19. Beck DE, Ferguson MA, Opelka FG, Fleshman JW, Gervaz P, Wexner SD. Effect of previous surgery on abdominal opening time. Dis Colon Rectum 2000;43:1749-53.

20. Liakakos T, Thomakos N, Fine PM, Dervenis C, Young RL. Peritoneal adhesions: etiology, pathophysiology, and clinical significance. Recent advances in prevention and management. Dig Surg 2001;18:260-73.

21. Coleman MG, McLain AD, Moran BJ. Impact of previous surgery on time taken for incision and division of adhesions during lapa- 
rotomy. Dis Colon Rectum 2000;43:1297-9.

22. El-Hakim A, Chiu KY, Sherry B, Bhuiya T, Smith AD, Lee BR. Peritoneal and systemic inflammatory mediators of laparoscopic bowel injury in a rabbit model. J Urol 2004;172(4 Pt 1):1515-9.

23. Van Der Krabben AA, Dijkstra FR, Nieuwenhuijzen M, Reijnen MM, Schaapveld M, Van Goor H. Morbidity and mortality of inadvertent enterotomy during adhesiotomy. Br J Surg 2000;87:46771.

24. Park SJ, Lee KY, Lee SH. Laparoscopic surgery for colorectal cancer in Korea: nationwide data from 2008-2013. J Minim Invasive Surgery 2015;18:39-43.

25. Veldkamp R, Kuhry E, Hop WC, Jeekel J, Kazemier G, Bonjer HJ, et al. Laparoscopic surgery versus open surgery for colon cancer: short-term outcomes of a randomised trial. Lancet Oncol 2005;6:
477-84.

26. Patel CB, Ragupathi M, Ramos-Valadez DI, Haas EM. A threearm (laparoscopic, hand-assisted, and robotic) matched-case analysis of intraoperative and postoperative outcomes in minimally invasive colorectal surgery. Dis Colon Rectum 2011;54:14450.

27. Kim JH, Lee IK, Kang WK, Oh ST, Kim JG, Lee YS. Initial experience of a surgical fellow in laparoscopic colorectal cancer surgery under training protocol and supervision: comparison of shortterm results for 70 early cases (under supervision) and 73 late cases (without supervision). Surg Endosc 2013;27:2900-6.

28. Park JW, Lim SW, Choi HS, Jeong SY, Oh JH, Lim SB. The impact of obesity on outcomes of laparoscopic surgery for colorectal cancer in Asians. Surg Endosc 2010;24:1679-85. 